\title{
Local infiltration anesthesia versus epidural analgesia for postoperative pain control in total knee arthroplasty: a systematic review and meta-analysis
}

\author{
Chen Li, Ji Qu, Su Pan and Yang Qu*
}

\begin{abstract}
Background: We performed a systematic review and meta-analysis of randomized controlled trials (RCTs) to evaluate the efficacy and safety of local infiltration anesthesia (LIA) versus epidural analgesia (EPA) for postoperative pain control in total knee arthroplasty (TKA).

Methods: In December 2017, a systematic computer-based search was conducted in Pubmed, EMBASE, Web of Science, and Cochrane Database of Systematic Reviews. RCTs of patients prepared for spine surgery that compared LIA versus EPA for postoperative pain control in TKA were retrieved. The primary endpoint was the VAS score with rest or mobilization at 12, 24 and 48, and $72 \mathrm{~h}$. The secondary outcomes were the range of motion, the length of stay, and the occurrence of infection and nausea. After testing for publication bias and heterogeneity between studies, data were aggregated for random-effects models when necessary.

Results: Seven clinical studies with 251 patients $(L I A=124, E P A=127)$ were included in the meta-analysis. There was no significant difference between LIA and EPA group in terms of the VAS score with rest at 12 and $24 \mathrm{~h}$. LIA was associated with a reduction of the VAS score with rest at 48 and $72 \mathrm{~h}$ than EPA $(P<0.05)$. There was no significant difference between the LIA group and EPA group in terms of the VAS with mobilization at 24,48 , and $72 \mathrm{~h}(P>0.05)$. And LIA was associated with an increase of the range of motion at 24 and $48 \mathrm{~h}(P<0.05)$ and a reduction of the length of hospital stay $(P<0.05)$. What is more, LIA was associated with a reduction of the occurrence of the nausea.

Conclusions: LIA has equivalent efficacy as EPA for pain control after TKA and shows an increase of the range of motion and a reduction of the occurrence of nausea and length of hospital stay. Due to the limited number of the included studies, more high-quality RCTs are still needed to identify the long-term effects of LIA for pain control after TKA.
\end{abstract}

Keywords: Local infiltration anesthesia, Total knee arthroplasty, Pain control, Meta-analysis

\section{Background}

Total knee arthroplasty (TKA) is a commonly performed procedure today. It was reported that over 700,000 joint replacements are performed in the USA each year [1]. However, postoperative analgesia remains a challenging issue. More than half of the patients undergoing TKA would experience severe pain in the early postoperative period [2-4]. Appropriate pain control is a prerequisite

* Correspondence: 272216821@qq.com

Department of orthopaedics, The Second Hospital of Jilin University,

Changchun, Jilin Province 130041, People's Republic of China to promoting early mobilization and functional recovery after TKA. Several options are available for postoperative pain management following TKA, but all of them have shortcomings.

Epidural analgesia consisting of a local anesthetic agent and an opioid has been a regular regimen used for postoperative analgesia after TKA. However, some studies have indicated that the benefit of epidural analgesia must be weighed against the frequency of its adverse effects such as urinary retention, hypotension, pruritus, and motor block that delays mobilization. 
In recent years, there is a growing interest in the use of local infiltration analgesia (LIA) containing various constituents as a modality of postoperative pain control. The advantage of LIA is the ability to provide pain control without interfering with lower extremity motor strength, thereby allowing early mobilization of patients. Studies have shown that LIA is consistently more effective in the treatment of postoperative pain after TKA when compared with placebo. There was still controversy about which protocol is more suitable for pain control after TKA. Therefore, we searched for relevant studies and performed a meta-analysis comparing LIA versus epidural anesthesia for reducing pain intensity in TKA patients.

\section{Methods}

This systematic review was reported according to the Preferred Reporting Items for Systematic Reviews and Meta-Analyses (PRISMA) guidelines.

\section{Search strategies}

The following databases were searched in November 2017 without restriction of regions or publication types: Pubmed (1950-November 2017), EMBASE (1974-November 2017), Web of Science (1950-November 2017), and Cochrane Library (November 2017 Issue 3). The Mesh terms and their combinations used in the search were as follows: "local infiltration anesthesia" OR "LIA" OR "epidural anesthesia" OR "EPA” AND ")(((“Arthroplasty, Replacement, Knee”[Mesh]) OR TKR) OR TKA) OR total knee replacement)" OR total knee arthroplasty. The reference lists of related reviews and original articles were searched for any relevant studies, including randomized controlled trials (RCTs) involving adult humans. Only articles originally written in English or translated into English were considered. When multiple reports describing the same sample were published, the most recent or complete report was used. Since this is a meta-analysis, no ethics committee or institutional review board approval was necessary for the study.

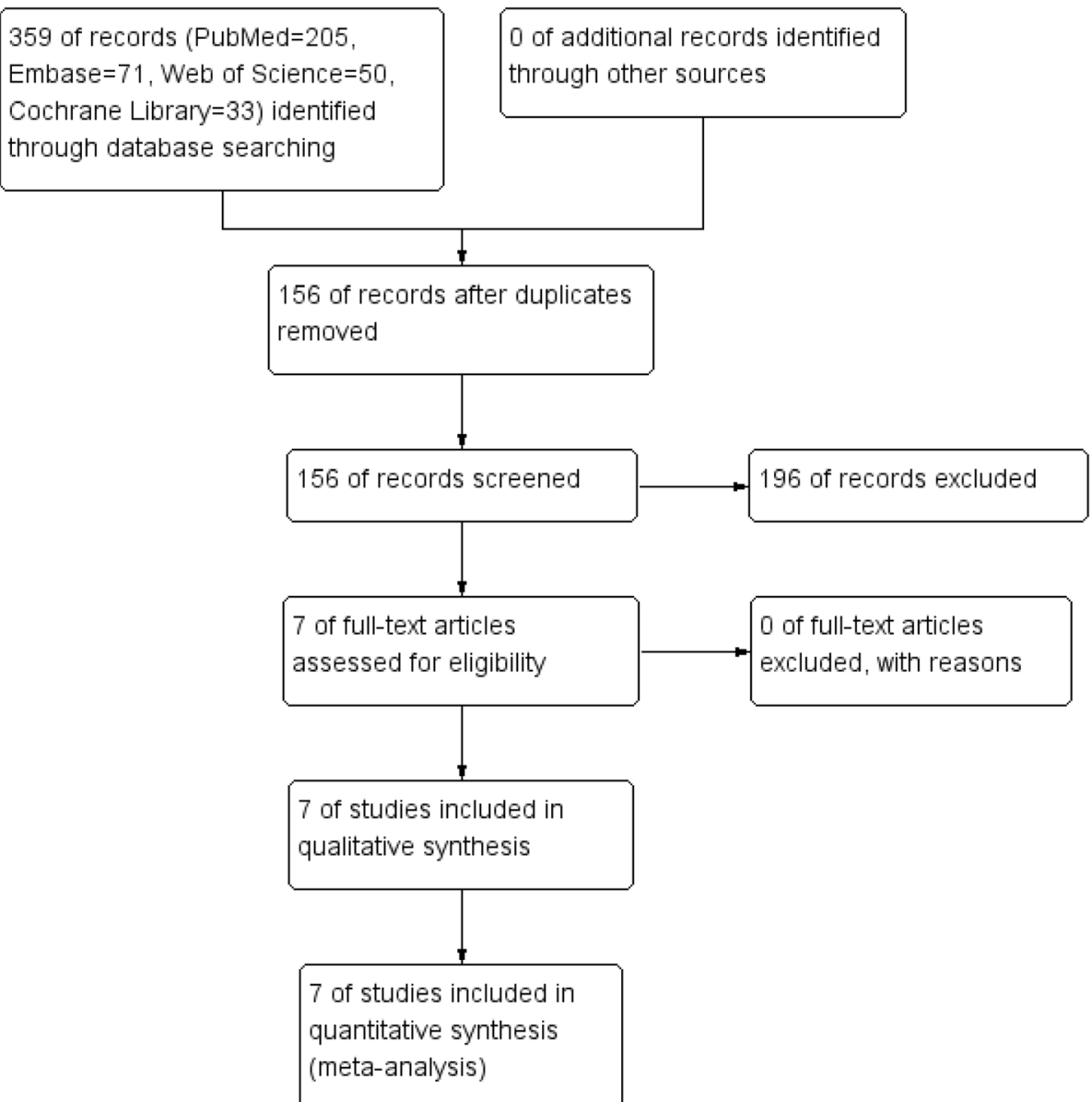

Fig. 1 Flowchart of study search and inclusion criteria 


\section{Inclusion criteria and study selection}

The following are included in the study: patients: adult human subjects prepared for TKA; intervention: LIA as an intervention group; comparison: EPA as a control group; outcomes: visual analogue scale (VAS) with rest or mobilization at $12,24,48$, and $72 \mathrm{~h}$, the length of hospital stay, and the occurrence of nausea and infection; and study design: RCTs. Two independent reviewers screened the title and abstracts of the identified studies after removing the duplicates of the search results. Any disagreements about the inclusion or exclusion of a study were solved by discussion or consultation with an expert. The reliability of the study selection was determined by Cohen's kappa test, and the acceptable threshold value was set at $0.61[5,6]$.

\section{Data abstraction and quality assessment}

A specific extraction was conducted to collect the following data from the included trials: patients' general characteristics, country, the sample size of the control group and intervention group, and the drug and dose of LIA and EPA. Outcomes such as VAS with rest or mobilization at $12,24,48$, and $72 \mathrm{~h}$; the length of hospital stay; and the occurrence of nausea and infection were abstracted and recorded in a sheet. Postoperative pain intensity was measured by a 100-point VAS. When the numerical rating scale (NRS) was reported, it was converted to a VAS. Additionally, a 10-point VAS was converted to a 100-point VAS [7]. Data in other forms (i.e., median, interquartile range, and mean $\pm 95 \%$ confidence interval (CI)) were converted to the mean \pm standard deviation (SD) according to the Cochrane Handbook [8]. If the data were not reported numerically, we extracted these data using "GetData Graph Digitizer" software from the published figures. All the data were extracted by two independent reviewers, and disagreements were resolved by discussion. The methodological quality of all included trials was independently assessed by two reviewers on the basis of the Cochrane Handbook for Systematic Reviews of Interventions, version 5.1.0 (http://www.cochrane-handbook.org/).

\section{Outcome measures and statistical analysis}

Continuous outcomes (VAS with rest or mobilization at $12,24,48$, and $72 \mathrm{~h}$ and the length of hospital stay) were expressed as the weighted mean differences (WMD) and respective 95\% CI. Dichotomous outcomes (the occurrence of nausea and infection) were expressed as the risk ratio (RR) with 95\% CI. Statistical significance was set at $P<0.05$ to summarize the findings across the trials. The meta-analysis was calculated by Stata software, version 12.0 (Stata Corp., College Station, TX). Statistical

Table 1 The general characteristic of the included studies

\begin{tabular}{|c|c|c|c|c|c|c|c|c|c|}
\hline \multirow[t]{2}{*}{ Author } & \multirow[t]{2}{*}{ Country } & \multirow{2}{*}{$\begin{array}{l}\text { Age } \\
\text { (year, l/C) }\end{array}$} & \multirow{2}{*}{$\begin{array}{l}\text { Male } \\
\text { patients } \\
(\%, \mathrm{l} / \mathrm{C})\end{array}$} & \multicolumn{2}{|l|}{ LIA } & \multicolumn{2}{|l|}{ EPA } & \multirow[t]{2}{*}{ Study } & \multirow[t]{2}{*}{ Follow-up } \\
\hline & & & & $\begin{array}{l}\text { No. of } \\
\text { patients }\end{array}$ & Dose and methods & $\begin{array}{l}\text { No. of } \\
\text { patients }\end{array}$ & Dose and methods & & \\
\hline $\begin{array}{l}\text { Andersen et al. } \\
2010[10]\end{array}$ & Denmark & $67 / 69$ & $50 / 40$ & 21 & $\begin{array}{l}\text { Combination of wound } \\
\text { infiltration and continuous } \\
\text { intra-articular injection } \\
\text { postoperatively }\end{array}$ & 19 & $\begin{array}{l}\text { Continuous epidural } \\
\text { infusion }\end{array}$ & RCTs & 30 days \\
\hline $\begin{array}{l}\text { Binici et al. } \\
2014 \text { [11] }\end{array}$ & Turkey & $70.8 / 67.9$ & $0 / 5$ & 15 & $\begin{array}{l}\text { Continuous peri-articular } \\
\text { injection postoperatively } \\
\text { ( } 3 \mathrm{ml} \text { ( } 60 \mathrm{mg} \text { ) lidocaine) }\end{array}$ & 15 & $\begin{array}{l}\text { Continuous epidural } \\
\text { infusion }\end{array}$ & $\mathrm{RCTs}$ & 7 days \\
\hline $\begin{array}{l}\text { Kasture and } \\
\text { Saraf } 2015 \\
{[12]}\end{array}$ & India & $67.2 / 67.5$ & $12 / 15$ & 40 & $\begin{array}{l}300 \mathrm{ml} \text { of } 0.125 \% \\
\text { bupivacaine with } 5 \mathrm{ml} \\
\text { ketorolac injection }\end{array}$ & 35 & $\begin{array}{l}\text { Continuous epidural } \\
\text { infusion ( } 300 \mathrm{ml} \text { of } \\
0.125 \% \text { bupivacaine } \\
\text { with } 300 \text { mcg fentanyl } \\
\text { injection) }\end{array}$ & $\mathrm{RCTs}$ & 1 month \\
\hline $\begin{array}{l}\text { Klasen et al. } \\
1999 \text { [13] }\end{array}$ & Germany & $70 / 69$ & $0 / 0$ & 10 & $\begin{array}{l}\text { Single infiltration (1 mg } \\
\text { morphine diluted in } 20 \\
\mathrm{ml} \text { of saline } 0.9 \% \text { ) }\end{array}$ & 10 & $\begin{array}{l}\text { Continuous epidural } \\
\text { infusion (boluses of } \\
2.5 \text { mg of morphine) }\end{array}$ & RCTs & 2 months \\
\hline $\begin{array}{l}\text { Spreng et al. } \\
2010[14]\end{array}$ & Norway & $67.2 / 65.8$ & $30 / 41$ & 37 & $\begin{array}{l}\text { Single-shot intraoperative } \\
\text { peri-articular infiltration } \\
\text { (ketorolac } 30 \mathrm{mg} \text { and } \\
\text { morphine } 5 \mathrm{mg} \text { ) }\end{array}$ & 33 & $\begin{array}{l}\text { Continuous epidural } \\
\text { infusion (ropivacaine } \\
150 \mathrm{mg} \text { and epinephrine } \\
0.5 \mathrm{mg} \text { added to isotonic } \\
\text { saline) }\end{array}$ & RCTs & 16 days \\
\hline $\begin{array}{l}\text { Tsukada et al. } \\
2014 \text { [15] }\end{array}$ & Japan & NS & NS & 50 & $\begin{array}{l}\text { Single-shot intraoperative } \\
\text { peri-articular infiltration }\end{array}$ & 61 & $\begin{array}{l}\text { Continuous epidural } \\
\text { infusion }\end{array}$ & RCTs & NS \\
\hline $\begin{array}{l}\text { Tsukada et al. } \\
2015[16]\end{array}$ & Japan & NS & NS & 37 & $\begin{array}{l}\text { Single-shot intraoperative } \\
\text { peri-articular infiltration }\end{array}$ & 33 & $\begin{array}{l}\text { Continuous epidural } \\
\text { infusion }\end{array}$ & $\mathrm{RCTS}$ & 6 months \\
\hline
\end{tabular}


heterogeneity was tested using the chi-squared test and $I^{2}$ statistic. When there was no statistical evidence of heterogeneity $\left(I^{2}<50 \%, P>0.1\right)$, a fixed-effects model was adopted; otherwise, a random-effect model was chosen. Publication bias was tested using funnel plots. Publication bias was assessed by funnel plot and quantitatively assessed by Begg's test. We considered there to be no publication bias if the funnel plot was symmetrical and the $P$ value was $>0.05$.

\section{Grade of evidence}

The quality of evidence for each finding was rated based on criteria established by the GRADE (Grading of Recommendations Assessment, Development and Evaluation) group [9]. The RCTs was considered as high-quality evidence, which could be downgraded to moderate, low, or very low quality for five reasons (high risk of bias, inconsistent results, indirect evidence, imprecision, and publication bias). Any disagreement was settled by discussion among the research team.

\section{Results}

\section{Search results and quality assessment}

Figure 1 details the study search and selection process. In the initial research, a total of 359 papers were identified from the electronic databases (PubMed $=205$, Embase $=71$, Web of Science $=50$, and Cochrane Library $=33$ ). The number of articles after duplicates had been removed by Endnote X7 software was 203. After screened the abstracts and title of these 203 studies, 196 papers were excluded because they were irrelevant or did not meet the criteria. Finally, a total of seven clinical studies involving 251 patients $(\mathrm{LIA}=124, \mathrm{EPA}=$ 127) were included in this meta-analysis [10-16]. The general characteristic of the included studies can be seen in Table 1. Included studies published from the year of 1995 to the year of 2015 . And the sample of the included studies ranged from 15 to 61 .

The risk of bias summary and risk of bias graph can be seen in Figs. 2 and 3. The random sequence generation was low risk of bias in five studies, and two studies were unclear risk of bias. The allocation concealment were low risk of bias in four studies, high risk of bias in one study, and unclear risk of bias in the rest of the studies. The blinding of participants and outcomes assessment were unclear risk of bias in four studies and the selection reporting were low risk of bias in all of the included studies.

\section{VAS with rest at $12,24,48$, and $72 \mathrm{~h}$}

Postoperative VAS scores with rest at $12 \mathrm{~h}$ were reported in six studies, and the pooled results indicated that there was no significant difference between the

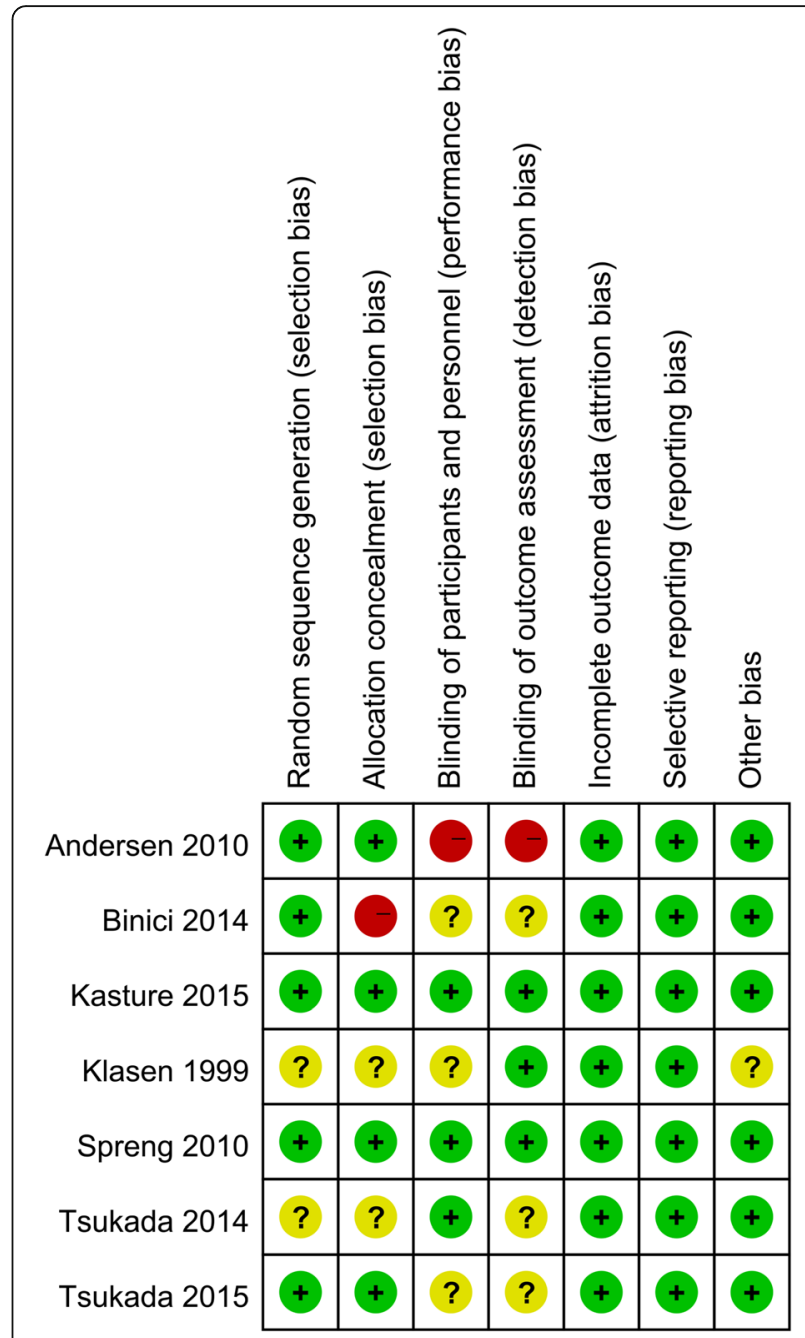

Fig. 2 Risk of bias summary of included randomized controlled trials. + , no bias; -, bias; ?, bias unknown

LIA and EPA group in terms of the VAS score with rest at $12 \mathrm{~h}(\mathrm{WMD}=-0.21,95 \% \mathrm{CI}-0.61,0.18, P=0$. 288, Fig. 4a). There were a total of seven clinical studies performing the results of VAS score with rest at $24 \mathrm{~h}$. Results indicated that there was no significant difference between the two groups as regard to the VAS score with rest at $24 \mathrm{~h}(\mathrm{WMD}=-0.29,95 \% \mathrm{CI}-$ $0.94,0.37, P=0.386$, Fig. $4 \mathrm{~b})$. VAS score with rest at $48 \mathrm{~h}$ were available in five studies, and pooled results indicated that LIA was associated with a reduction of the VAS score with rest at $48 \mathrm{~h}$ than EPA (WMD = 1.09, 95\% CI $-2.09,-0.09, P=0.032$, Fig. 4c). VAS score with rest at $72 \mathrm{~h}$ were available in five studies, and pooled results indicated that LIA was associated with a reduction of the VAS score with rest at $72 \mathrm{~h}$ than EPA (WMD $=-0.88,95 \% \mathrm{CI}-1.29,-0.46, P=0$. 000, Fig. 4d). 


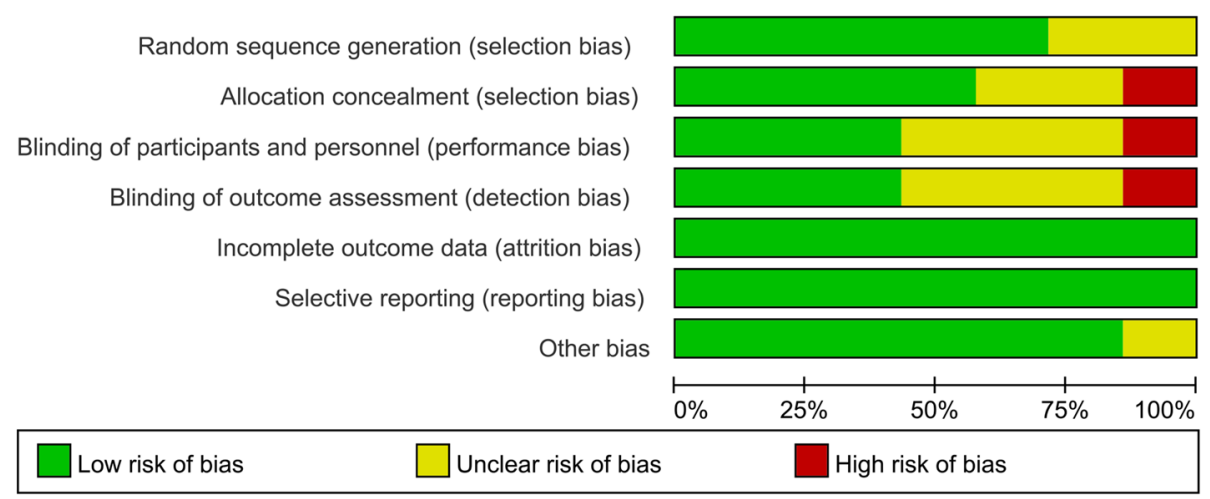

Fig. 3 The risk of bias graph

VAS with mobilization at 24,48 , and $72 \mathrm{~h}$

There were no significant differences between the LIA group versus EPA group in VAS score with mobilization at $24 \mathrm{~h}(\mathrm{WMD}=0.08,95 \% \mathrm{CI}-1.88,2.05, P=0.934$, Fig. 5a), $48 \mathrm{~h}$ (WMD $=-0.45,95 \% \mathrm{CI}-2.25,1.36, P=0$. 627, Fig. 5b) and $72 \mathrm{~h}(\mathrm{WMD}=-1.25,95 \% \mathrm{CI}-2.54,0$. 05, $P=0.060$, Fig. 5c).

\section{Range of motion at 24,48 , and $72 \mathrm{~h}$}

Meta-analysis results indicated that LIA was associated with an increase of the range of motion than EPA at $24 \mathrm{~h}(\mathrm{WMD}=5.44,95 \%$ CI $0.29,10.79, P=0$. 039, Fig. 6) and $48 \mathrm{~h}(\mathrm{WMD}=5.21,95 \% \mathrm{CI} 1.01,9$. 42, $P=0.015$, Fig. 6). The pooled results indicated that there was no significant difference between LIA

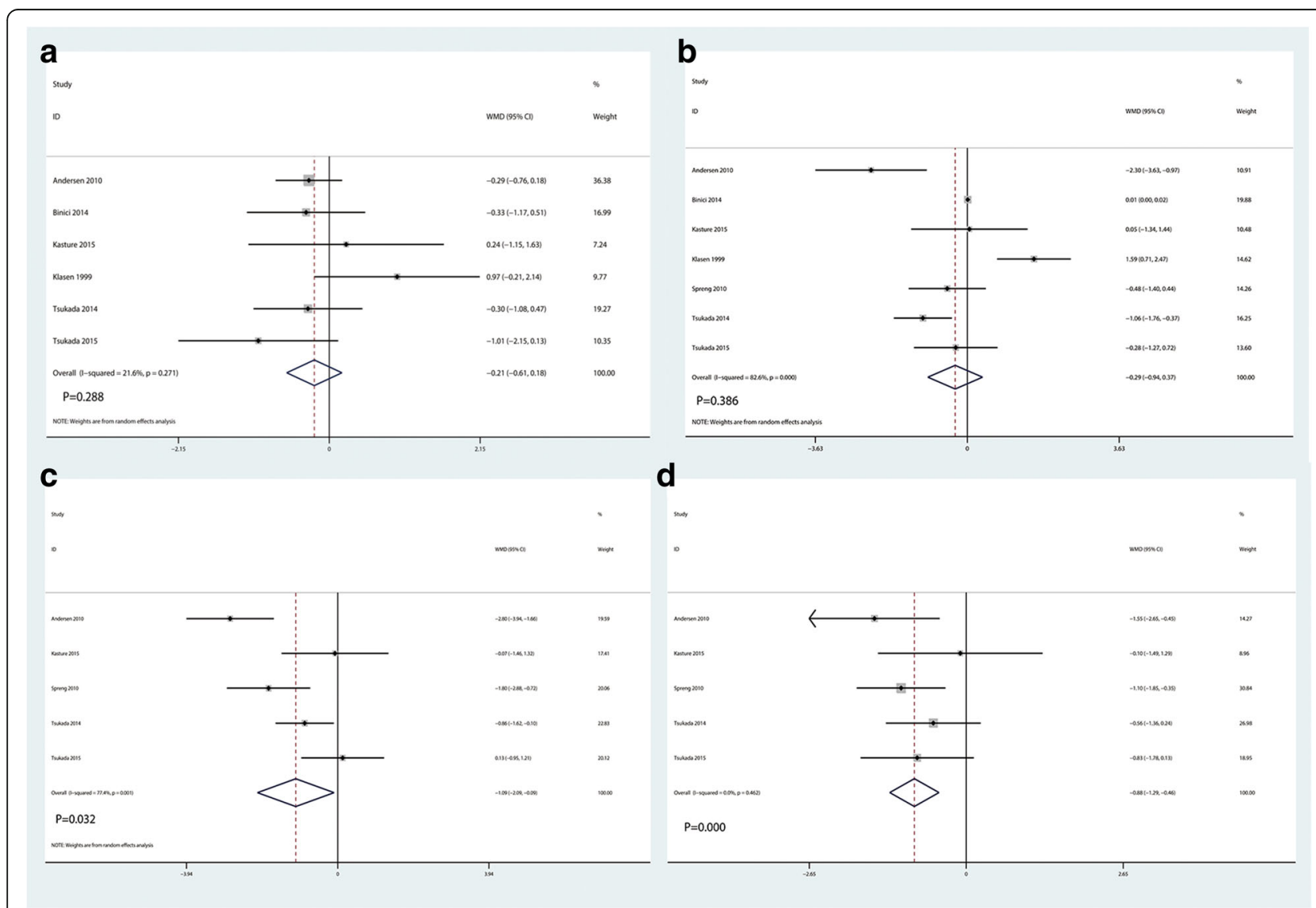

Fig. 4 Forest plots of the included studies comparing the VAS with rest at $12 \mathrm{~h} \mathrm{(a),} 24 \mathrm{~h} \mathrm{(b)}, 48 \mathrm{~h}(\mathbf{c})$, and $72 \mathrm{~h}$ (d) 


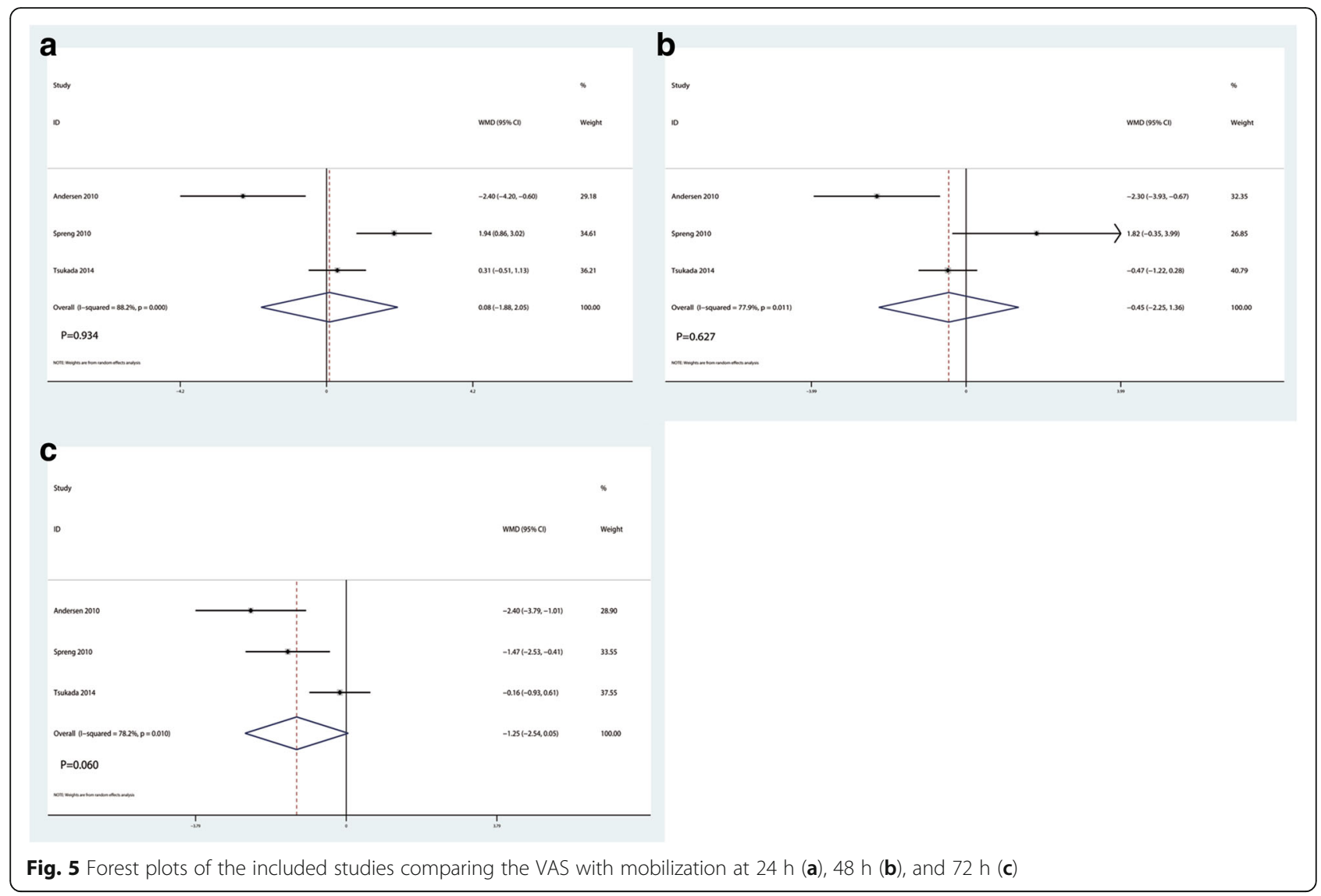

group and EPA in terms of range of motion at $72 \mathrm{~h}$ (WMD $=-1.25,95 \% \mathrm{CI}-2.54,0.05, P=0.060$, Fig. 6 ).

\section{Length of hospital stay}

Meta-analysis results indicated that LIA was associated with a reduction of the LOS than EPA (WMD $=-1.71$, 95\% CI $-3.12,-0.30, P=0.018$, Fig. 7).

\section{The occurrence of nausea and infection}

Meta-analysis results indicated that LIA was associated with a reduction of the occurrence of nausea than EPA $(\mathrm{RR}=0.38,95 \%$ CI $0.26,0.57, P=0.000$, Fig. 8). There was no significant difference between the LIA group and EPA group in terms of the occurrence of infection $(\mathrm{RR}=1.98,95 \%$ CI 0.50, 7.81, $P=0.331$, Fig. 9).

\section{Grade of evidence}

Grade of evidence was low in VAS with rest or mobilization at 12, 24, 48, and $72 \mathrm{~h}$. And the grade of evidence was high in the length of hospital stay and the occurrence of nausea and infection. Grade of evidence was middle in the range of motion at 24,48 , and $72 \mathrm{~h}$.

\section{Publication bias, sensitivity analysis, and subgroup analysis}

Funnel plot analyses on VAS with rest at $12,24,48$, and $72 \mathrm{~h}$ demonstrated symmetry, suggesting that bias was minimal (Fig. 10). Firstly, we applied leave-out method by excluding some studies to reduce between-study heterogeneity, thereby making a more robust conclusion (Fig. 11). The conclusions remained unchanged in all outcomes, suggesting the stability of our meta-analysis. We further conducted a subgroup analysis for VAS scores (single-shot LIA or continuous LIA). Subgroup result of VAS with rest at $12,24,48$, and $72 \mathrm{~h}$ was shown in Additional file 1: Figure S1. Subgroup difference was found in VAS with rest at $48 \mathrm{~h}$ (single-shot LIA, WMD $=-2.80,95 \%$ CI $-3.94,-1.66, P=0.000$; continuous LIA, WMD $=-0.69,95 \% \mathrm{CI}-1.51,0.12$, $P=0.093)$. VAS with mobilization at 24,48 , and $72 \mathrm{~h}$ was shown in Additional file 2: Figure S2. Subgroup difference was found in VAS with mobilization at 48 and $72 \mathrm{~h}$.

\section{Discussion}

Summary of the main finding

Current meta-analysis indicated that LIA has an equivalent efficacy for pain relieving with rest of mobilization 
Study

ID
WMD $(95 \% \mathrm{Cl})$

Weight

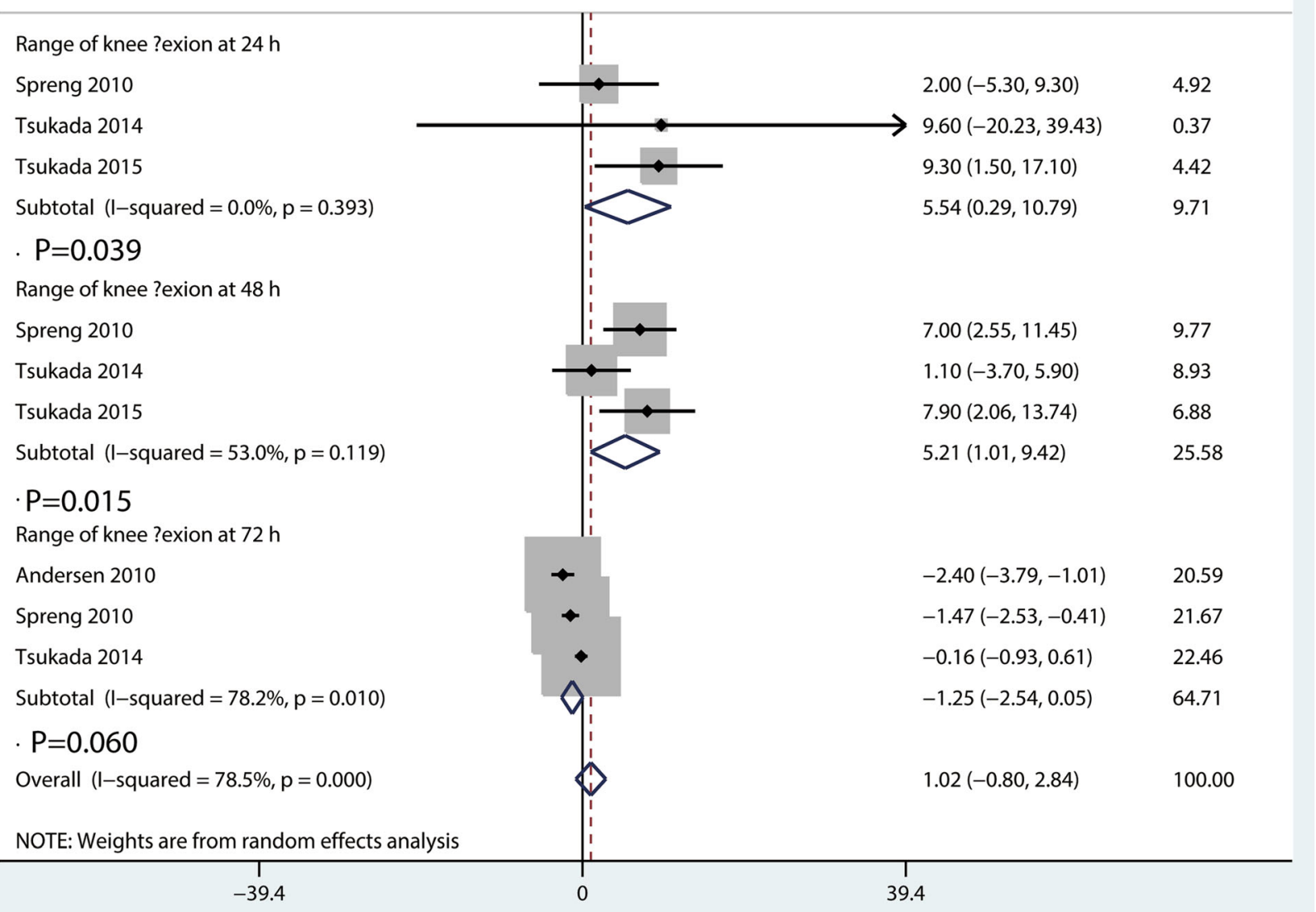

Fig. 6 Forest plots of the included studies comparing the range of motion at 24,48 , and $72 \mathrm{~h}$

at early period and late period than EPA after TKA. LIA was associated with an increase of the range of motion than EPA at an early period after TKA. And LIA was associated with a reduction of the occurrence of nausea and the length of hospital stay than EPA. There was no significant difference between the occurrence of infection. Yan et al. [17] conducted a recent meta-analysis of RCTs showing that LIA achieves better analgesic effects comparing with EPA. However, it contained some methodological shortcomings, errors in inclusion criteria (TKA and total hip arthroplasty (THA)) and data extraction, and high heterogeneity. Considering all these issues, it is impossible to give clear advice on which method to adopt.

Pain intensity was measured as VAS score at 12, 24, 48, and $72 \mathrm{~h}$ after TKA. Choi et al. [18] performed a Cochrane review and revealed that EPA may be useful for postoperative pain relief at early (four to $6 \mathrm{~h}$ ) postoperative period following TKA. These results were in accordance with our main results. Jiménez-Almonte et al. [19] using the novel statistical network metaanalysis approach and found no differences between LIA and EPA in terms of analgesia or opioid consumption $24 \mathrm{~h}$ after total hip arthroplasty.

With respect to the range of motion of the knee, we found that LIA was superior than EPA in the early period after TKA. These may not be an indicator of favorable pain control in the LIA group. It is more likely attributed to the absence of motor block. As a result, early functional recovery will be strengthened by functional quadriceps [20].

Current meta-analysis also compared the occurrence of nausea and infection. Epidural analgesia consisting a variety of opioids and identified has a beneficial role in reducing pain intensity after surgeries. However, the results of many studies showed a high frequency of 


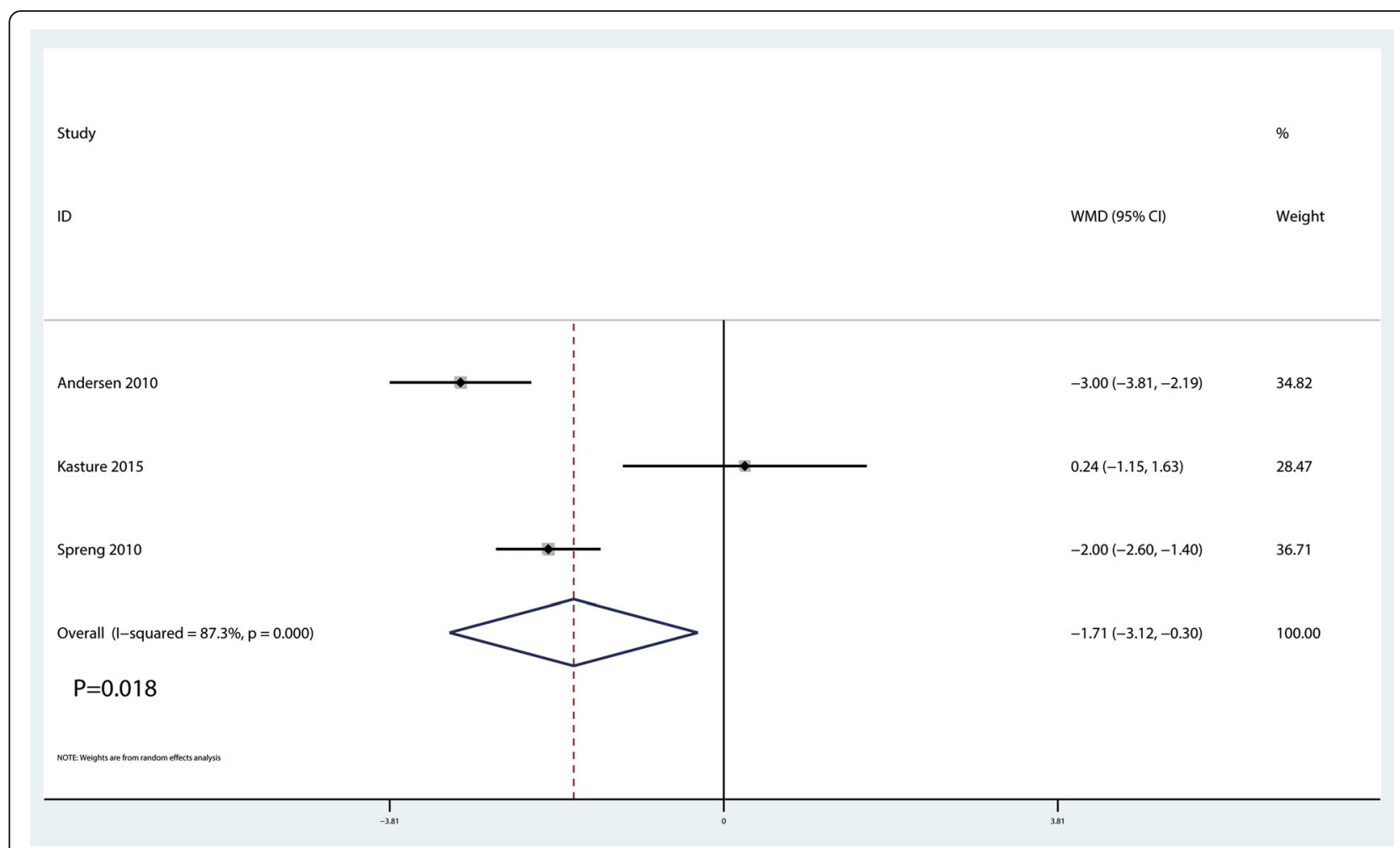

Fig. 7 Forest plots of the included studies comparing the length of hospital stay between the two groups

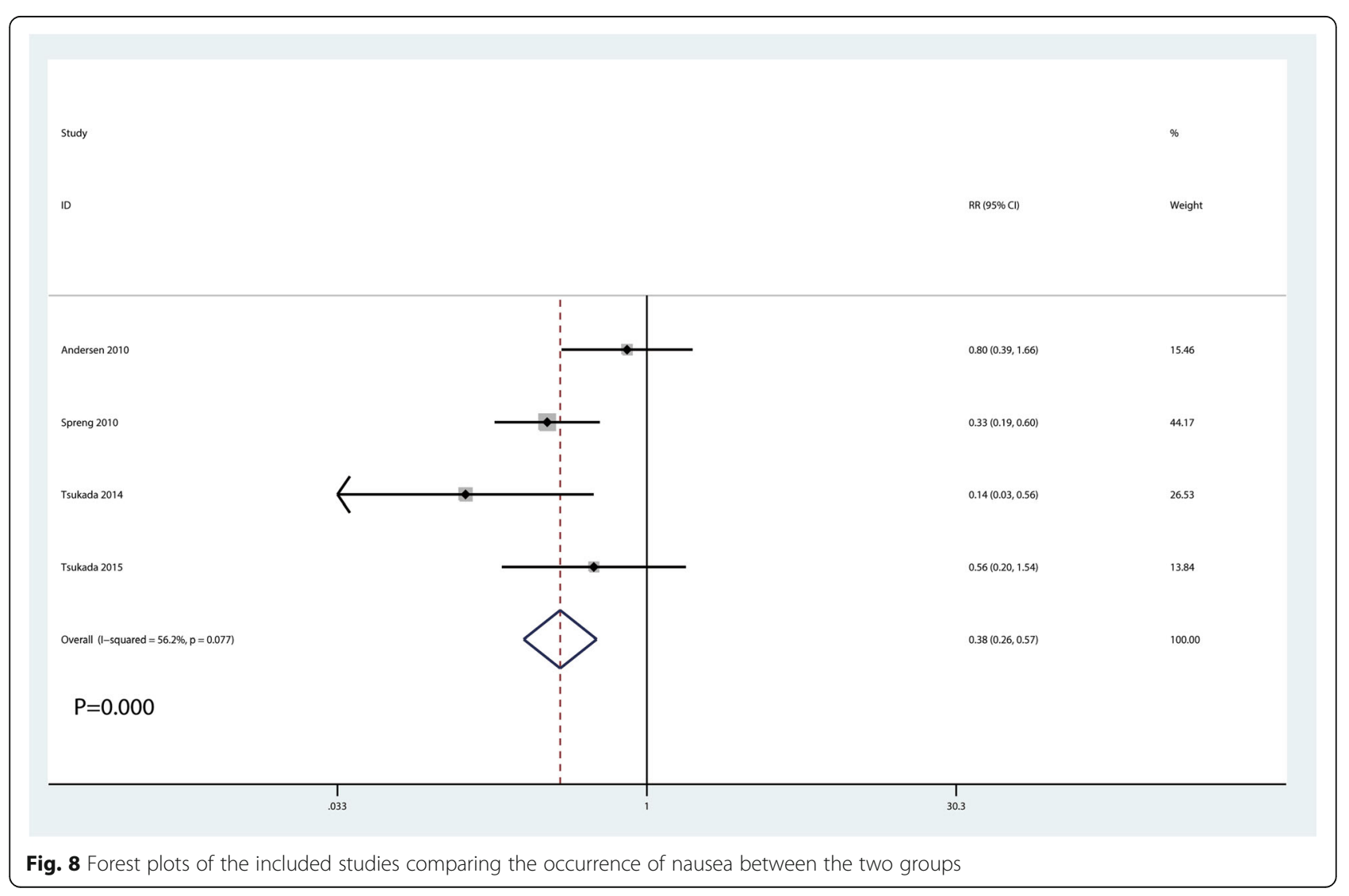



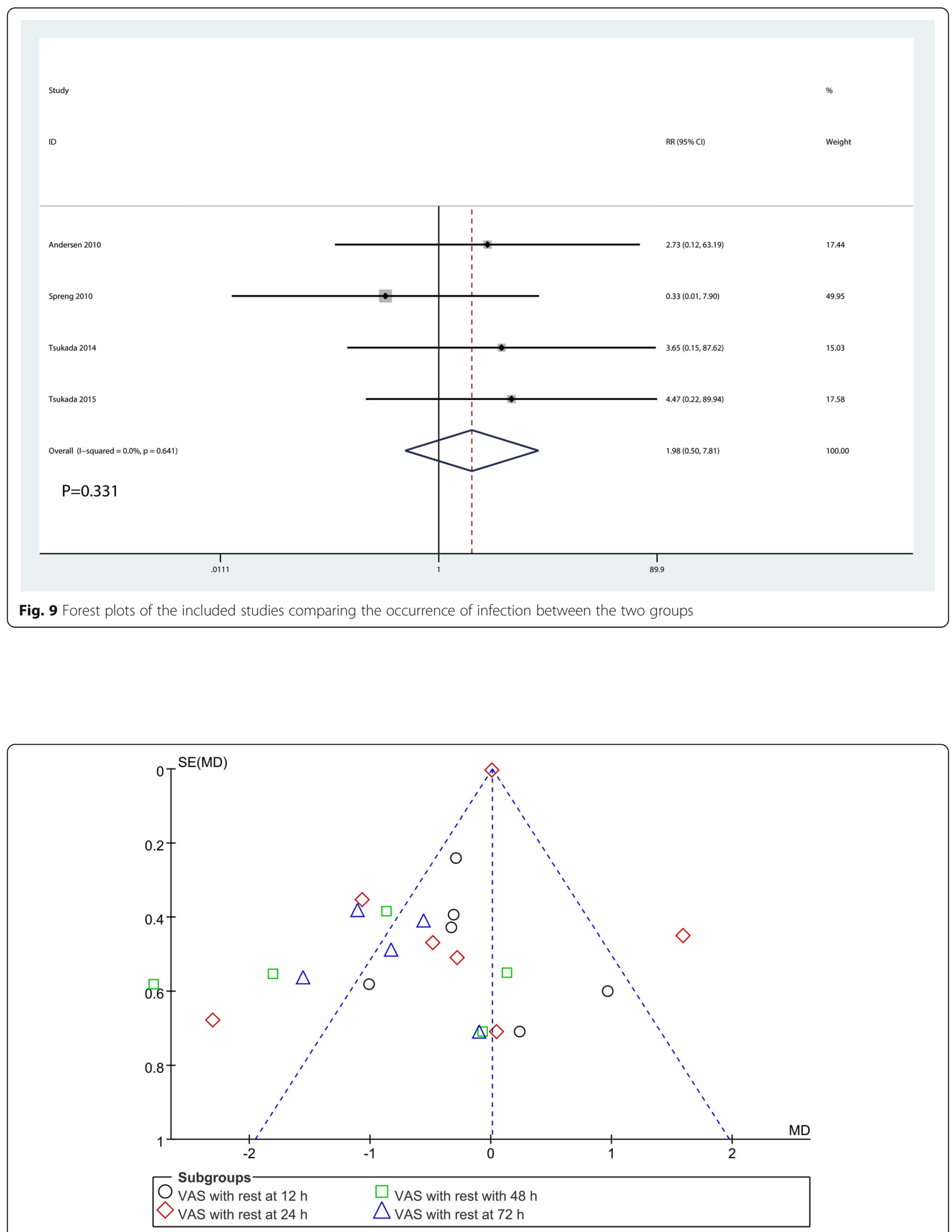

Fig. 10 Funnel plot that comparing the VAS with rest at $12,24,48$, and $72 \mathrm{~h}$ 


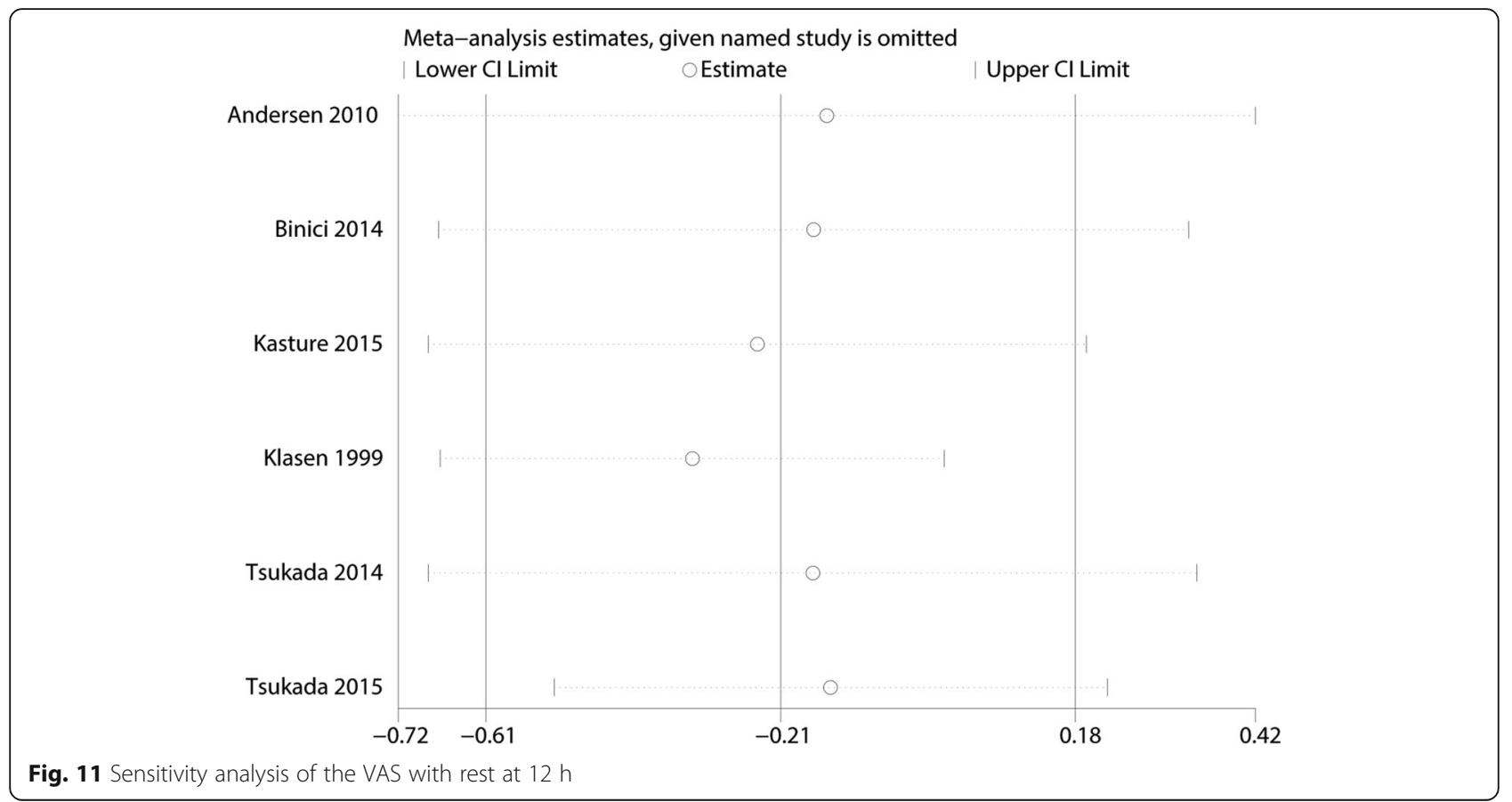

nausea or vomiting [21]. local anesthesia was accepted as the gold standard for postoperative pain control after the report by Bromage et al. [22]. Results shown that LIA was associated with a reduction of the occurrence of nausea than EPA. More nausea has been reported to occur with morphine than with local infiltration anesthesia $[23,24]$. This can be considered a disadvantage of the epidural method. In terms of wound infection, incidences were comparable between groups and kept at low level. There was no significant difference between the occurrence of infection.

\section{Limitations and strengths}

Our meta-analysis also has several potential limitations that should be taken into account when considering the benefits. First, our analysis comprised only seven RCTs, but one of them had a modest sample size $(n<100)$. Compared to large sample size studies, small sample size studies are inclined to overestimate the intervention effect [25], which limits the power of inference. Second, although the effect size in the funnel plot was symmetrical, we could not exclude the publication bias due to the small number of the included studies. Meanwhile, the relative short follow-up duration will underestimate the complications.

\section{Conclusion}

Although the overall quality of the evidence can be considered "middle," we objectively assessed the benefits and risk of LIA and EPA. Based on this meta-analysis of all currently published RCTs, the findings have important implications for the medical community, namely, that LIA is an effective alternative to provide less length of hospital stay and nausea but provides comparable level of pain relief in comparison with the EPA.

\section{Additional files}

Additional file 1: Figure S1. Subgroup analysis of the VAS with mobilization at 24, 48, and $72 \mathrm{~h}$ (single-shot local infiltration anesthesia or continuous local infiltration anesthesia, A VAS with rest at $24 \mathrm{~h}, \mathrm{~B}$ VAS with rest at $48 \mathrm{~h}$, and C VAS with rest at $72 \mathrm{~h}$ ). (DOCX $1384 \mathrm{~kb}$ )

Additional file 2: Figure S2. Subgroup analysis of the VAS with rest at $12,24,48$, and 72 h (single-shot local infiltration anesthesia or continuous local infiltration anesthesia, A VAS with rest at $12 \mathrm{~h}, \mathrm{~B}$ VAS with rest at $24 \mathrm{~h}$, C VAS with rest at 48 h, D VAS with rest at 72 h). (DOCX 2027 kb)

\section{Abbreviations}

Cl: Confidence interval; EPA: Epidural analgesia; LIA: Local infiltration anesthesia; NRS: Numerical rating scale; PRISMA: Preferred Reporting Items for Systematic Reviews and Meta-Analyses; RCTs: Randomized controlled trials; RR: Risk ratio; SD: Standard deviation; THA: Total hip arthroplasty; TKA: Total knee arthroplasty; VAS: Visual analogue scale; WMD: Weighted mean differences

Acknowledgements

No funding was required for this systematic review and meta-analysis.

Funding

There is no funding for this article. 


\section{Availability of data and materials}

I state that data will not be shared since all the raw data can be seen in the figures in my article.

\section{Authors' contributions}

CL and J Q conceived the design of the study. S P and Y Q performed and collected the data and contributed to the design of the study. C L and J Q prepared and revised the manuscript. All authors read and approved the final content of the manuscript.

\section{Ethics approval and consent to participate}

Not applicable.

\section{Consent for publication}

Not applicable.

\section{Competing interests}

The authors declare that they have no competing interests.

\section{Publisher's Note}

Springer Nature remains neutral with regard to jurisdictional claims in published maps and institutional affiliations.

Received: 3 January 2018 Accepted: 15 March 2018

Published online: 16 May 2018

\section{References}

1. Kurtz S, Ong K, Lau E, Mowat F, Halpern M. Projections of primary and revision hip and knee arthroplasty in the United States from 2005 to 2030. J Bone Joint Surg Am. 2007;89(4):780-5.

2. Maheshwari AV, Blum YC, Shekhar L, Ranawat AS, Ranawat CS. Multimodal pain management after total hip and knee arthroplasty at the Ranawat Orthopaedic center. Clin Orthop Relat Res. 2009:467(6):1418-23.

3. Zhu Y, Feng Y, Peng L. Effect of transcutaneous electrical nerve stimulation for pain control after total knee arthroplasty: a systematic review and metaanalysis. J Rehabil Med. 2017;49(9):700-4.

4. Xing Q, Dai W, Zhao D, Wu J, Huang C, Zhao Y. Adductor canal block with local infiltrative analgesia compared with local infiltrate analgesia for pain control after total knee arthroplasty: a meta-analysis of randomized controlled trials. Medicine (Baltimore). 2017;96(38):e8103.

5. Landis JR, Koch GG. An application of hierarchical kappa-type statistics in the assessment of majority agreement among multiple observers. Biometrics. 1977;33(2):363-74.

6. Landis JR, Koch GG. The measurement of observer agreement for categorical data. Biometrics. 1977;33(1):159-74.

7. Wang C, Cai X-Z, Yan S-G. Comparison of periarticular multimodal drug injection and femoral nerve block for postoperative pain management in total knee arthroplasty: a systematic review and meta-analysis. J Arthroplast. 2015;30(7):1281-6.

8. GS HJ. Cochrane handbook for systematic reviews of interventions version 5.1.0[updated March 2011]. 2011, 2011.

9. Balshem $\mathrm{H}$, Helfand $\mathrm{M}$, Schunemann HJ, et al. GRADE guidelines: 3. Rating the quality of evidence. J Clin Epidemiol. 2011;64(4):401-6.

10. Andersen KV, Bak M, Christensen BV, Harazuk J, Pedersen NA, Soballe K. A randomized, controlled trial comparing local infiltration analgesia with epidural infusion for total knee arthroplasty. Acta Orthop. 2010;81(5):606-10.

11. Binici Bedir E, Kurtulmus T, Basyigit S, Bakir U, Saglam N, Saka G. A comparison of epidural analgesia and local infiltration analgesia methods in pain control following total knee arthroplasty. Acta Orthop Traumatol Turc. 2014;48(1):73-9.

12. Kasture $\mathrm{S}$, Saraf H. Epidural versus intra-articular infusion analgesia following total knee replacement. J Orthop Surg (Hong Kong). 2015;23(3):287-9.

13. Klasen JA, Opitz SA, Melzer C, Thiel A, Hempelmann G. Intraarticular, epidural, and intravenous analgesia after total knee arthroplasty. Acta Anaesthesiol Scand. 1999;43(10):1021-6.

14. Spreng UJ, Dahl V, Hjall A, Fagerland MW, Raeder J. High-volume local infiltration analgesia combined with intravenous or local ketorolac +morphine compared with epidural analgesia after total knee arthroplasty. Br J Anaesth. 2010;105(5):675-82.

15. Tsukada S, Wakui M, Hoshino A. Postoperative epidural analgesia compared with intraoperative periarticular injection for pain control following total knee arthroplasty under spinal anesthesia: a randomized controlled trial. J Bone Joint Surg Am. 2014;96(17):1433-8.

16. Tsukada S, Wakui M, Hoshino A. Pain control after simultaneous bilateral total knee arthroplasty: a randomized controlled trial comparing periarticular injection and epidural analgesia. J Bone Joint Surg Am. 2015; 97(5):367-73.

17. Yan H, Cang J, Xue Z, Lu J, Wang H. Comparison of local infiltration and epidural analgesia for postoperative pain control in total knee arthroplasty and total hip arthroplasty: a systematic review and meta-analysis. Bosn J Basic Med Sci. 2016;16(4):239-46.

18. Choi PT, Bhandari M, Scott J, Douketis J. Epidural analgesia for pain relief following hip or knee replacement. Cochrane Database Syst Rev. 2003;3: Cd003071.

19. Jimenez-Almonte JH, Wyles CC, Wyles SP, et al. Is local infiltration analgesia superior to peripheral nerve blockade for pain management after THA: a network meta-analysis. Clin Orthop Relat Res. 2016;474(2):495-516.

20. Hu B, Lin T, Yan SG, et al. Local infiltration analgesia versus regional blockade for postoperative analgesia in total knee arthroplasty: a metaanalysis of randomized controlled trials. Pain Physician. 2016;19(4):205-14.

21. Block BM, Liu SS, Rowlingson AJ, Cowan AR, Cowan JA Jr, Wu CL. Efficacy of postoperative epidural analgesia: a meta-analysis. JAMA. 2003;290(18):2455-63.

22. Bromage PR, Camporesi E, Chestnut D. Epidural narcotics for postoperative analgesia. Anesth Analg. 1980;59(7):473-80.

23. Andersen LO, Kristensen BB, Husted H, Otte KS, Kehlet $\mathrm{H}$. Local anesthetics after total knee arthroplasty: intraarticular or extraarticular administration? A randomized, double-blind, placebo-controlled study. Acta Orthop. 2008; 79(6):800-5.

24. Vendittoli PA, Makinen P, Drolet P, et al. A multimodal analgesia protocol for total knee arthroplasty. A randomized, controlled study. J Bone Joint Surg Am. 2006;88(2):282-9.

25. Zhang Z, Xu X, Ni H. Small studies may overestimate the effect sizes in critical care meta-analyses: a meta-epidemiological study. Crit Care. 2013; 17(1):R2.

\section{Submit your next manuscript to BioMed Central} and we will help you at every step:

- We accept pre-submission inquiries

- Our selector tool helps you to find the most relevant journal

- We provide round the clock customer support

- Convenient online submission

- Thorough peer review

- Inclusion in PubMed and all major indexing services

- Maximum visibility for your research

Submit your manuscript at www.biomedcentral.com/submit
Ciomed Central 